This article was downloaded by: [National Taiwan University]

On: 16 December 2008

Access details: Access Details: [subscription number 788846425]

Publisher Taylor \& Francis

Informa Ltd Registered in England and Wales Registered Number: 1072954 Registered office: Mortimer House, 37-41 Mortimer Street, London W1T 3JH, UK

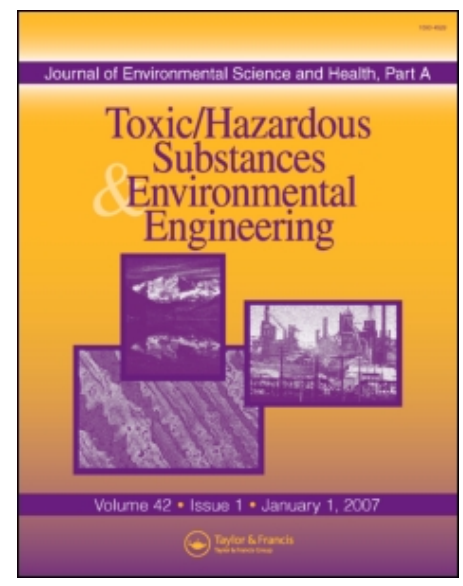

Journal of Environmental Science and Health, Part A

Publication details, including instructions for authors and subscription information:

http://www.informaworld.com/smpp/title content=t713597268

\title{
Adsorption of Copper and Lead lons onto Regenerated Sludge from a Water Treatment Plant
}

Chung-Hsin Wu a; Cheng-Fang Lin b; Pay-Yu Horng ${ }^{b}$

a Department of Environmental Engineering and Health, Yuanpei University of Science and Technology,

Hsinchu, Taiwan, R.O.C. ${ }^{\mathrm{b}}$ Graduate Institute of Environmental Engineering, National Taiwan University,

Taipei, Taiwan, R.O.C.

Online Publication Date: 02 January 2005

To cite this Article Wu, Chung-Hsin, Lin, Cheng-Fang and Horng, Pay-Yu(2005)'Adsorption of Copper and Lead lons onto Regenerated Sludge from a Water Treatment Plant',Journal of Environmental Science and Health, Part A,39:1,237 — 252 To link to this Article: DOI: $10.1081 / \mathrm{ESE}-120027381$

URL: http://dx.doi.org/10.1081/ESE-120027381

PLEASE SCROLL DOWN FOR ARTICLE

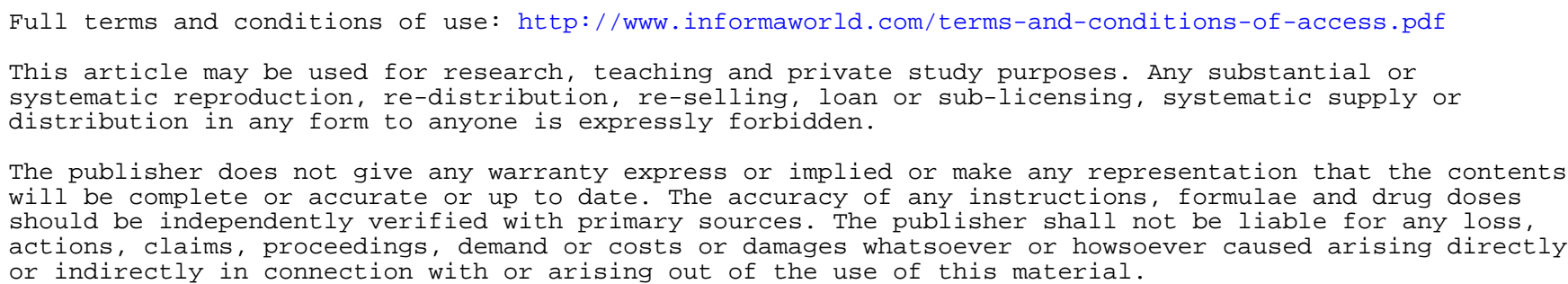


JOURNAL OF ENVIRONMENTAL SCIENCE AND HEALTH

Part A-Toxic/Hazardous Substances \& Environmental Engineering

Vol. A39, No. 1, pp. 237-252, 2004

\title{
Adsorption of Copper and Lead Ions onto Regenerated Sludge from a Water Treatment Plant
}

\author{
Chung-Hsin $\mathrm{Wu},{ }^{1, *}$ Cheng-Fang Lin, ${ }^{2}$ and Pay-Yu Horng ${ }^{2}$ \\ ${ }^{1}$ Department of Environmental Engineering and Health, \\ Yuanpei University of Science and Technology, Hsinchu, Taiwan, R.O.C. \\ ${ }^{2}$ Graduate Institute of Environmental Engineering, \\ National Taiwan University, Taipei, Taiwan, R.O.C.
}

\begin{abstract}
In this study, water treatment sludges were sintered under various experimental conditions to generate Al-containing adsorbents. The adsorption of $\mathrm{Cu}^{2+}$ and $\mathrm{Pb}^{2+}$ onto sintered oxide was examined and sorption results were further modeled using a surface complex model. The specific surface area of the sintered adsorbent was substantially reduced from $30 \mathrm{~m}^{2} / \mathrm{g}$ (dried sludge) to $2 \mathrm{~m}^{2} / \mathrm{g}$ (sinter sludge). The $\mathrm{pH}$-adsorption-edges of both $\mathrm{Cu}^{2+}$ and $\mathrm{Pb}^{2+}$ were shifted towards a higher $\mathrm{pH}$ than the edges of the unsintered adsorbent, revealing reduced affinity of the sintered adsorbent for metal ions. Metal leaching was measured by the TCLP procedure, and the results indicated that the amount of metal leaching by the sintered adsorbent was negligible. The effect of background electrolytes on $\mathrm{Cu}^{2+}$ and $\mathrm{Pb}^{2+}$ sorption was negligible. Triple-layer model (TLM) simulation revealed that $\mathrm{Cu}^{2+}$ and $\mathrm{Pb}^{2+}$ sorption on sintered adsorbent involves inner-sphere interactions and the dominant surface metal species are monodentates of $\mathrm{Me}^{2+}$ and $\mathrm{MeOH}^{+}$. The intrinsic adsorption constants of $\mathrm{Cu}^{2+}$ and $\mathrm{Pb}^{2+}$ on dried
\end{abstract}

*Correspondence: Chung-Hsin Wu, Department of Environmental Engineering and Health, Yuanpei University of Science and Technology, 306 Yuanpei St., Hsinchu 300, Taiwan, R.O.C.; Fax: 886-3-5385353; E-mail: chwu@mail.yust.edu.tw. 
sludge, adsorbent sintered at $1000^{\circ} \mathrm{C}$, and adsorbent sintered at $1100^{\circ} \mathrm{C}$ were also examined.

Key Words: $\mathrm{Cu}^{2+} ; \mathrm{Pb}^{2+}$; Water treatment sludge; Sinter; Adsorption; Surface complex model; TLM.

\section{INTRODUCTION}

Large amounts of sludge are generated from water treatment plants in Taiwan. The quantity and disposal of water treatment sludge generated during purification is of concern. According to various analyses, sludge from water treatment includes various oxides such as silicon oxide, calcium oxide, iron oxide, and aluminum oxide and a large quantity of clay. If these oxide resources can be appropriately recycled, then the need to dispose of wastes will be reduce and, indirectly, the need for natural resources will also be reduced.

Karius and Hamer ${ }^{[1]}$ characterized a brick made of harbor sediments (50\% wt.) from the port of Bremen-City. Their results indicated that thermal treatment of the sediments at $1050^{\circ} \mathrm{C}$ immobilized most of the trace contaminants. Wiebusch et al. ${ }^{[2]}$ found that the amount of heavy metal released from bricks made of sewage sludge was markedly reduced by sintering, and so the environmental compatibility of recycled material could be ensured. The first task in recycling water treatment sludge is to prevent it from being altered by changing circumstances during its application. The inclusion of harmful substances in the water treatment sludge is limited by sintering, preventing their dissolution. Many studies have found that the dominant sludge contaminant can be immobilized within a sintered product. ${ }^{[3,4]}$ The water treatment sludge can then be recycled as a sinter.

Silicon oxide, iron oxide, and aluminum oxide have large surface areas, and so are frequently used as adsorbents in adsorption reactions performed to elucidate the adsorptive behavior at solid/liquid interfaces. The water treatment sludge produced during water purification contains much silicon, iron, and aluminum oxide. These substances can be reused as adsorbents after they are sintered.

Pure adsorbents are now being substituted by natural by-products or stabilized solid materials in the development of cost-effective composite adsorbents that can treat various contaminants. Gupta and Torres ${ }^{[5]}$ as well as Ayala et al. ${ }^{[6]}$ used fly ash as an adsorbent to remove the heavy metals in wastewater and proved that recycled fly ash is an excellent substance for use as an adsorbent for removing heavy metals from wastewater. Meng et al. ${ }^{[7]}$ used tire rubber as an adsorbent for removing mercury ions, and showed that used tire rubber can absorb many mercury ions at a $\mathrm{pH}$ between two and eight. Apak et al. ${ }^{[8]}$ and Lopez et al. ${ }^{[9]}$ examined the feasibility of using less expensive material - red mud - to remove cadmium and zinc from wastewater. Mohan et al. ${ }^{[10]}$ used activated carbon derived from fertilizer waste material to adsorb mercury from wastewater. Mohan and Singh ${ }^{[1]}$ used activated carbon derived from bagasse to remove cadmium and zinc from wastewater. Motivated the sustainable development, this work applies sintering to transform water treatment sludge into a resource that can be used as an adsorbent to remove 
heavy metals during wastewater treatment. The aims of this work are as follows: (i) to elucidate the equilibrium adsorption reaction of heavy metals (copper and lead) onto the sintered material surface, (ii) to compare the adsorption on various sintered materials and dried sludge surfaces, (iii) to simulate these adsorption results using TLM, and (iv) to transform the water treatment sludge into a resource and use it as an adsorbent to remove heavy metals from wastewater.

\section{MATERIALS AND METHODS}

\section{Preparation of Adsorbent}

The adsorbent used in this study was prepared as follows: Smash and screen the dried water treatment sludge; pour 5 to $6 \%$ deionized water onto it, and shape it at a pressure of 2 ton $/ \mathrm{cm}^{2}$. Sinter the shaped water treatment sludge at $1000^{\circ} \mathrm{C}$ or $1100^{\circ} \mathrm{C}$ for $60 \mathrm{~min}$. Smash and screen the sinter to reduce the diameter of the powder until it will pass through a 200 mesh, to increase the area of contact with the adsorbent during the reaction. Wash the sintered powder before performing the adsorption, to remove the impurities from the surface and thus prevent any inconsistency of the functional groups on the surface of the sinter from influencing the adsorption. The washing process is described as follows.

(i) Mix the sintered powder that has passed through the 200 mesh sieve with Milli-Q deionized water and leave the mixture to undergo reverse osmosis through a funnel.

(ii) Soak the sintered powder that has undergone reverse osmosis with a large amount of deionized water and regularly replace the deionized water. The washing is completed when the electrical conductivity of the water used to wash the sintered powder is the same as that of the deionized water.

(iii) Take the sintered powder out of the reverse osmosis device to separate the solid from the liquid. Then, place the sintered powder in an oven and dry it at $103^{\circ} \mathrm{C}$.

The sintered powder thus treated was the adsorbent used herein. The composition of the water treatment sludge was analyzed using inductively coupled plasma atomic emission spectroscopy (ICP-AES).

\section{Sorption Experiments}

The agents used were all reagent grade. Each $0.1 \mathrm{M} \mathrm{of} \mathrm{Cu}^{2+}$ and $\mathrm{Pb}^{2+}$ stock solutions were prepared using $\mathrm{Cu}\left(\mathrm{NO}_{3}\right)_{2}, \mathrm{~Pb}\left(\mathrm{NO}_{3}\right)_{2}$, and Milli-Q deionized water, respectively. $\mathrm{NaNO}_{3}$ solution was added in the sorption experiments to maintain the concentration of the background electrolyte of the system, at $0.1 \mathrm{M}, 0.01 \mathrm{M}$, or $0.001 \mathrm{M}$. Zero point two five grams of each of the three adsorbents was weighed and $50 \mu \mathrm{L}$ of the cation stock solution was used. The $\mathrm{pH}$ of the solution was adjusted 
using $0.1 \mathrm{~N} \mathrm{HNO}_{3}$ and $0.1 \mathrm{~N} \mathrm{NaOH}$, between 3 and 11 . The total volume was then fixed to $50 \mathrm{~mL}$. The solid/liquid ratio of the adsorbent in the taper bottle was $5 \mathrm{~g} / \mathrm{L}$ and the concentration of the cations was $10^{-4} \mathrm{M}$. Nitrogen was added to remove the gas from under the surface of the solution and from the bottle, preventing $\mathrm{CO}_{2}$ from affecting the $\mathrm{pH}$ of the system. Then, the bottle was plugged with a rubber cork and sealed it using parafilm. It was placed in a vibration tank at a constant temperature of $25 \pm 0.1{ }^{\circ} \mathrm{C}$ and vibrated at $150 \mathrm{rpm}$ as the reaction proceeded. When the reaction was completed, the $\mathrm{pH}$ in the bottle was measured, and the sample moved to a centrifuge tube. The centrifuge tube was centrifuged at $9500 \mathrm{rpm}$ for $30 \mathrm{~min}$. The sample was filtered through $0.2 \mu \mathrm{m}$ filter film (PVDF Syringe Filter, $0.2 \mu \mathrm{m}$ ) and the remaining concentration of the cations measured using an atomic adsorption spectrometer. The percentage of the cations adsorbed by the adsorbent during the sorption experiment was calculated.

\section{Model Analysis}

A modified triple-layer complex model ${ }^{[12]}$ and the HYDRAQL program ${ }^{[13]}$ are selected to simulate the equilibrium adsorption reaction of the cations with the water treatment sludge and the sintered material.

Equations (1) and (2) specify the protonation of reacting surface sites, and Eqs. (3) and (4) describe the generation of complexes between the background electrolyte ions and the surface.

$$
\begin{aligned}
& \mathrm{SOH}_{2}^{+} \leftrightarrow \mathrm{SOH}+\mathrm{H}^{+} \\
& K_{a 1}^{\mathrm{int}}=\frac{[\mathrm{SOH}]\left\{\mathrm{H}^{+}\right\}}{\left[\mathrm{SOH}_{2}^{+}\right]} \exp \left(\frac{-\Psi_{0} F}{R T}\right) \\
& \mathrm{SOH} \leftrightarrow \mathrm{SO}^{-}+\mathrm{H}^{+} \\
& K_{a 2}^{\text {int }}=\frac{\left[\mathrm{SO}^{-}\right]\left\{\mathrm{H}^{+}\right\}}{[\mathrm{SOH}]} \exp \left(\frac{-\Psi_{0} F}{R T}\right) \\
& \mathrm{SOH}+\mathrm{Na}^{+} \leftrightarrow \mathrm{SO}^{-}-\mathrm{Na}^{+}+\mathrm{H}^{+} \\
& K_{\mathrm{Na}^{+}}^{\mathrm{int}}=\frac{\left[\mathrm{SO}^{-}-\mathrm{Na}^{+}\right]\left\{\mathrm{H}^{+}\right\}}{[\mathrm{SOH}]\left[\mathrm{Na}^{+}\right]} \exp \left[\frac{\left(\varphi_{\beta}-\varphi_{0}\right) F}{R T}\right] \\
& \mathrm{SOH}+\mathrm{H}^{+}+\mathrm{NO}_{3}^{-} \leftrightarrow \mathrm{SOH}_{2}^{+}-\mathrm{NO}_{3}^{-} \\
& K_{\mathrm{NO}_{3}^{-}}^{\mathrm{int}}=\frac{\left[\mathrm{SOH}_{2}^{+}-\mathrm{NO}_{3}^{-}\right]}{[\mathrm{SOH}]\left\{\mathrm{H}^{+}\right\}\left[\mathrm{NO}_{3}^{-}\right]} \exp \left[\frac{\left(\varphi_{0}-\varphi_{\beta}\right) F}{R T}\right]
\end{aligned}
$$
follows.

A possible equilibrium adsorption reaction of cations with the oxide surface is as

(i) If the adsorption of cations is visualized as a chemically specific reaction, then the reaction can be expressed as an inner-sphere coordination process. 
Metal ions with 1 and 2 mol of reactive surface hydroxyl form inner-sphere monodentate and bidentate surface complexes, respectively (Eqs. (5) and (6)).

$$
\begin{aligned}
& \mathrm{SOH}+\mathrm{M}^{2+}=\mathrm{SOM}^{+}+\mathrm{H}^{+} \\
& K_{\mathrm{M} 1}^{\mathrm{int}}=\frac{\left[\mathrm{SOM}^{+}\right]\left[\mathrm{H}^{+}\right]}{[\mathrm{SOH}]\left[\mathrm{M}^{2+}\right]} \exp \left(\frac{\Psi_{0} F}{R T}\right) \\
& 2 \mathrm{SOH}+\mathrm{M}^{2+}=(\mathrm{SO})_{2} \mathrm{M}+2 \mathrm{H}^{+} \\
& K_{\mathrm{M} 2}^{\mathrm{int}}=\frac{\left[(\mathrm{SO})_{2} \mathrm{M}\right]\left[\mathrm{H}^{+}\right]^{2}}{[\mathrm{SOH}]^{2}\left[\mathrm{M}^{2+}\right]}
\end{aligned}
$$

(ii) If cations react like a background electrolyte with $\mathrm{SOH}$, then ion-pairs are formed on the $\beta$-plane (Eq. (7)), on which the adsorption is nonspecific and the reaction product is an outer-sphere surface complex.

$$
\begin{aligned}
& \mathrm{SOH}+\mathrm{M}^{2+}=\mathrm{SO}^{-}-\mathrm{M}^{2+}+\mathrm{H}^{+} \\
& K_{\mathrm{M} 3}^{\mathrm{int}}=\frac{\left[\mathrm{SO}-\mathrm{M}^{+}\right]\left[\mathrm{H}^{+}\right]}{[\mathrm{SOH}]\left[\mathrm{M}^{2+}\right]} \exp \left(\frac{\left(2 \Psi_{\beta}-\Psi_{0}\right) F}{R T}\right)
\end{aligned}
$$

(iii) Equations (8) and (9) indicate that hydrate metal ions react with $\mathrm{SOH}$ and form inner-sphere and outer-sphere complexes, respectively.

$$
\begin{aligned}
& \mathrm{SOH}+\mathrm{M}^{2+}+\mathrm{H}_{2} \mathrm{O}=\mathrm{SOMOH}+2 \mathrm{H}^{+} \\
& K_{\mathrm{M} 4}^{\mathrm{int}}=\frac{[\mathrm{SOMOH}]\left[\mathrm{H}^{+}\right]^{2}}{[\mathrm{SOH}]\left[\mathrm{M}^{2+}\right]} \\
& \mathrm{SOH}+\mathrm{M}^{2+}+\mathrm{H}_{2} \mathrm{O}=\mathrm{SO}^{-}-\mathrm{MOH}^{+}+2 \mathrm{H}^{+} \\
& K_{\mathrm{M} 5}^{\mathrm{int}}=\frac{[\mathrm{SO}-\mathrm{MOH}]\left[\mathrm{H}^{+}\right]^{2}}{[\mathrm{SOH}]\left[\mathrm{M}^{2+}\right]} \exp \left(\frac{\left(\Psi_{\beta}-\Psi_{0}\right) F}{R T}\right)
\end{aligned}
$$

\section{RESULTS AND DISCUSSION}

\section{Composition of Water Treatment Sludge}

The water treatment sludge used in this study was obtained from Taipei's Chih-Tan Water Treatment Plant. The amount of sludge produced by that plant is approximately $2.66 \times 10^{5} \mathrm{~m}^{3} / \mathrm{yr}(98 \%$ wt. $)$. The water treatment sludge is concentrated and dried to form water treatment sludge cakes, which are then smashed, ground, and dried to meet the requirements of this research. Table 1 shows 
Table 1. Composition of the water treatment sludge.

\begin{tabular}{lc}
\hline Component & Percentage $(\mathrm{wt} \%)$ \\
\hline $\mathrm{SiO}_{2}$ & 53.58 \\
$\mathrm{Al}_{2} \mathrm{O}_{3}$ & 20.94 \\
$\mathrm{Fe}_{2} \mathrm{O}_{3}$ & 6.63 \\
$\mathrm{MgO}$ & 1.85 \\
$\mathrm{CaO}$ & 0.30 \\
$\mathrm{PbO}_{2}$ & 0.15 \\
$\mathrm{CuO}$ & 0.05 \\
$\mathrm{ZnO}$ & 0.04 \\
$\mathrm{Cr}$ & $\mathrm{O}_{3}$ \\
$\mathrm{CdO}$ & 0.03 \\
\end{tabular}

that the water treatment sludge includes various metal oxides, predominantly silicon oxide (50-55\%), aluminum oxide (20-30\%), and iron oxide (6-7\%), which represent approximately $80 \%$ of all the water treatment sludge. Gupta and Torres ${ }^{[5]}$ and Ayala et al. ${ }^{[6]}$ used fly ash as an adsorbent to remove heavy metals from wastewater. As expected, the water treatment sludge and its sinter can remove heavy metals from wastewater since fly ash is composed of $\mathrm{SiO}_{2}(43-53 \%), \mathrm{Al}_{2} \mathrm{O}_{3}(24-28 \%)$, and $\mathrm{Fe}_{2} \mathrm{O}_{3}(6-10 \%)$, a composition closely resembling that of the water treatment sludge.

\section{Characteristics of Adsorbent Surface}

The analysis conducted using a scanning electron microscope (SEM) reveals that unsintered dried water treatment sludge has a loose slice-shaped surface, while the surface of the sintered water treatment sludge is finer. Unlike the glossy surface of the sintered water treatment sludge, the surface of the granular water treatment sludge that is not sintered clearly exhibits several small slices. When the surface of the water treatment sludge sintered at $1000^{\circ} \mathrm{C}$ is much glossier, it retains many tiny holes. However, the surface of the water treatment sludge sintered at $1100^{\circ} \mathrm{C}$ is finer and without obvious holes. The surface area of the water treatment sludge is therefore suggested to be somewhat changed by sintering, such that the range of the change may depend on the temperature of the sintering.

Table 2 describes the surface areas of the three adsorbents used herein. The specific surface area is sharply reduced when the water treatment sludge is sintered at high temperature, because the powder is coherent and becomes dense due to atomic diffusion at high temperatures during the sintering. The coherence of the grains (namely, the growth of the neck between the grains) during sintering tightens the arrangement of the atoms of the sample; consequently, the holes become smaller and the specific surface area declines. The surface area of the dried water treatment sludge is much greater than that of the fly ash used by Ayala et al ${ }^{[6]}$ and Gupta and Torres ${ }^{[5]}$; however, the surface area of the sintered material is similar to that of the fly ash. This finding also confirms that the surface area of a product treated at a higher temperature is smaller. 
Table 2. Specific surface area of different adsorbent.

\begin{tabular}{ccc}
\hline Adsorbent & Sintered temperature $\left({ }^{\circ} \mathrm{C}\right)$ & Specific surface area $\left(\mathrm{m}^{2} / \mathrm{g}\right)$ \\
\hline I & Unsintered (dried sludge) & 30.5 \\
II & 1,000 & 3.1 \\
III & 1,100 & 2.0 \\
\hline
\end{tabular}

Table 3. TLM parameters and basic surface complexation constants. ${ }^{[14]}$

\begin{tabular}{lc}
\hline Specific surface area $\left(\mathrm{m}^{2} / \mathrm{g}\right)$ & BET measurement \\
\hline Site Density $\left(\right.$ site $\left./ \mathrm{nm}^{2}\right)$ & 5.0 \\
$\mathrm{C}_{1}\left(o\right.$-plane capacitance, $\left.\mu \mathrm{F} / \mathrm{cm}^{2}\right)$ & 125 \\
$\mathrm{C}_{2}\left(\beta\right.$-plane capacitance, $\left.\mu \mathrm{F} / \mathrm{cm}^{2}\right)$ & 20 \\
$\log K_{\mathrm{a} 1}^{\text {int }}, \log K_{\mathrm{a} 2}^{\text {int }}$ & $-1.5,-5.5$ \\
$\log K_{\mathrm{Na}+}^{\text {int }} \log K_{\mathrm{NO} 3^{-}}^{\text {int }}$ & $-7.0,-1.5$ \\
\hline
\end{tabular}

Basic surface complexing parameters of $\mathrm{SiO}_{2}$ are included in the sequent adsorption model simulation since $\mathrm{SiO}_{2}$ constitutes over $50 \%$ of water treatment sludge. Table 3 presents the suggested parameters in the simulation of adsorption on the surface of $\mathrm{SiO}_{2}$, with reference to the research of Meng and Latterman. ${ }^{[14]}$

The concentration of the heavy metals dissolved out of the sintered material is determined by the toxicity characteristic leaching procedure (TCLP), to evaluate the potential of the metals for causing harm when the sintered material is reused to treat wastewater. The results indicate that the concentrations of $\mathrm{Pb}$ and $\mathrm{Cr}$ dissolved from the $1000^{\circ} \mathrm{C}$ sintered material (Adsorbent II) are 0.051 and $0.008 \mathrm{mg} / \mathrm{L}$ respectively, while those in the water treatment sludge sintered at $1100^{\circ} \mathrm{C}$ (Adsorbent III) are 0.098 and $0.008 \mathrm{mg} / \mathrm{L}$, respectively. No Cd is dissolved in either case. The results in this study imply that the water treatment sludge recycled by sintering does not contain harmful dissolved heavy metals.

\section{Equilibrium Adsorption of $\mathrm{Cu}^{2+}$ and $\mathrm{Pb}^{2+}$ onto Water Treatment Sludge}

Figure 1 depicts the adsorption reaction of copper ions onto the surface of the water treatment sludge. According to the results of the test, the adsorption ratio increases with $\mathrm{pH}$, implying that the negative charge on the surface of the water treatment sludge increases with the $\mathrm{pH}$, facilitating the adsorption of the cations. However, changing the concentration of the background electrolyte does not strongly influence the adsorption of the copper ions; the maximum adsorption density is approximately $6.56 \times 10^{-7} \mathrm{~mol} / \mathrm{m}^{2}$. Hayes and Leckie ${ }^{[12]}$ determined that the effect of the background electrolyte on the adsorption reaction can be used to predict the adsorption reaction. $\beta$-plane adsorption can be assumed to occur when the background electrolyte easily influences the reaction; otherwise, $o$-plane adsorption may occur. Consequently, copper ions undergo an o-plane complex 


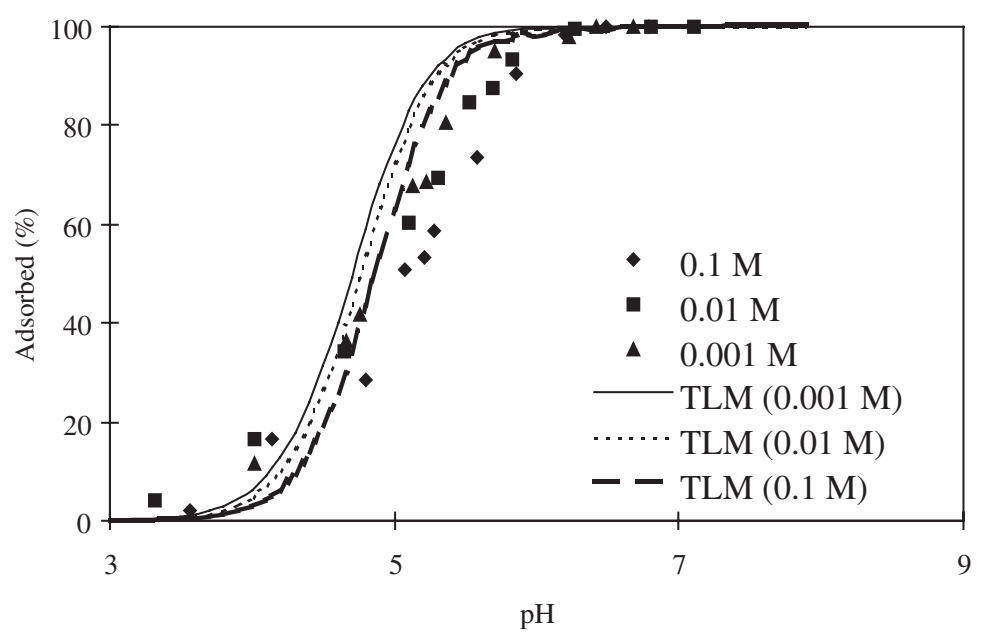

Figure 1. Adsorption of $\mathrm{Cu}^{2+}$ onto water treatment sludge (Adsorbent $\mathrm{I}$ ) as a function of $\mathrm{pH}$ under various background $\mathrm{NaNO}_{3}$ concentrations. Lines denote TLM results using $\mathrm{SOCu}^{+}+\mathrm{SOCuOH}$ of Eq. (5) + Eq. (8). Symbols denote experimental data.

reaction, without being impacted by the $\beta$-plane complex reaction of the background electrolyte $\left(\mathrm{Na}^{+}\right.$and $\left.\mathrm{NO}_{3}^{-}\right)$. When the copper ions undergo an o-plane complex reaction, the adsorption of $\mathrm{SOCu}^{+}$or $\mathrm{SOCuOH}$ occurs. The intrinsic equilibrium constants, $\log K_{\mathrm{SOCu}}^{\text {int }}$ and $\log K_{\mathrm{SOCuOH}}^{\mathrm{int}}$, of both reaction mechanisms are -6.35 and -6.9 , respectively. With respect to the co-existing complexes of $\mathrm{SOCu}^{+}$and $\mathrm{SOCuOH}$, the simulation is strongly consistent with the experimental results (Fig. 1): the free copper ion $\left(\mathrm{Cu}^{2+}\right)$ and the hydrate ion $\left(\mathrm{Cu}(\mathrm{OH})^{+}\right)$co-exist on the innersphere and form a coordination complex. Ayala et al. ${ }^{[6]}$ determined that the concentration of the background electrolytes does not affect the adsorption of $\mathrm{Cu}$ and $\mathrm{Cd}$ onto fly ash. This result is consistent with those obtained herein.

Figure 2 summarizes the results concerning the equilibrium adsorption of lead ions on the surface of water treatment sludge. The adsorption of the lead ions is similar to that of copper ions. Both substances are adsorbed onto the inner-sphere of the water treatment sludge, without being influenced by the background electrolyte concentration. The intrinsic equilibrium constants $\left(\log K_{\mathrm{SOPb}}^{\mathrm{int}}\right.$ and $\left.\log K_{\mathrm{SOPbOH}}^{\text {int }}\right)$ of lead ions are -6.75 and -7.25 , respectively. As for $\mathrm{Cu}^{2+}$, the results of the TLM simulation closely match the experimental results obtained when the co-existence of $\mathrm{Pb}^{2+}$ and $\mathrm{Pb}(\mathrm{OH})^{+}$in the system is considered (Fig. 2).

\section{Equilibrium Adsorption of $\mathrm{Cu}^{2+}$ and $\mathrm{Pb}^{2+}$ on Sintered Material}

Figures 3 and 4 plot the results of the equilibrium adsorption of copper ions on the surfaces of Adsorbents II and III. The equilibrium adsorption reaction of copper ions on Adsorbent II is slightly influenced by the concentration of the background electrolyte, especially when the concentration of the background electrolyte is high 


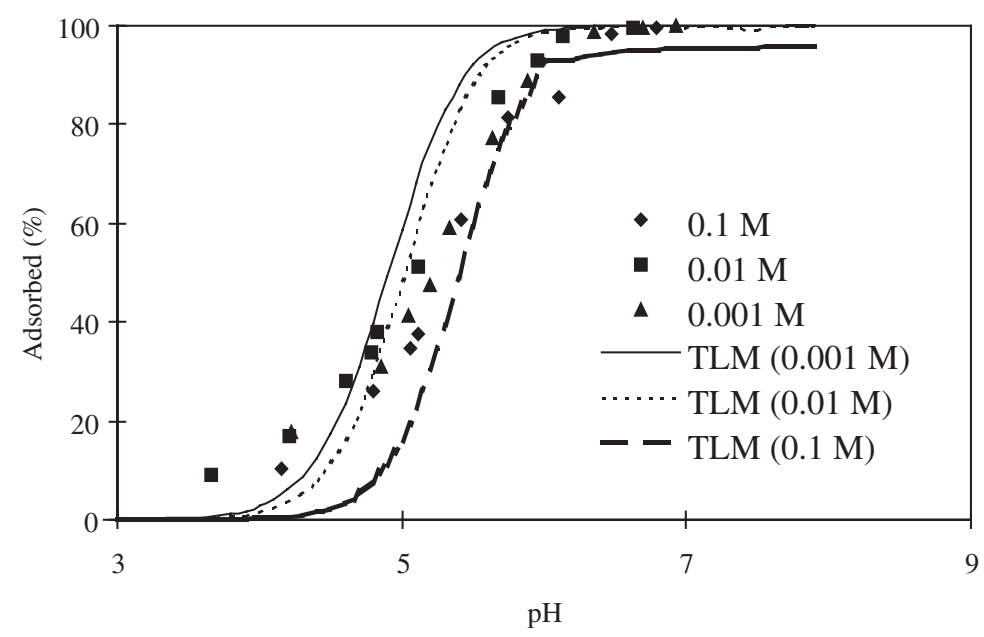

Figure 2. Adsorption of $\mathrm{Pb}^{2+}$ onto water treatment sludge (Adsorbent $\mathrm{I}$ ) as a function of $\mathrm{pH}$ under various background $\mathrm{NaNO}_{3}$ concentrations. Lines denote TLM results using $\mathrm{SOPb}^{+}+\mathrm{SOPbOH}$ of Eq. (5) + Eq. (8). Symbols denote experimental data.

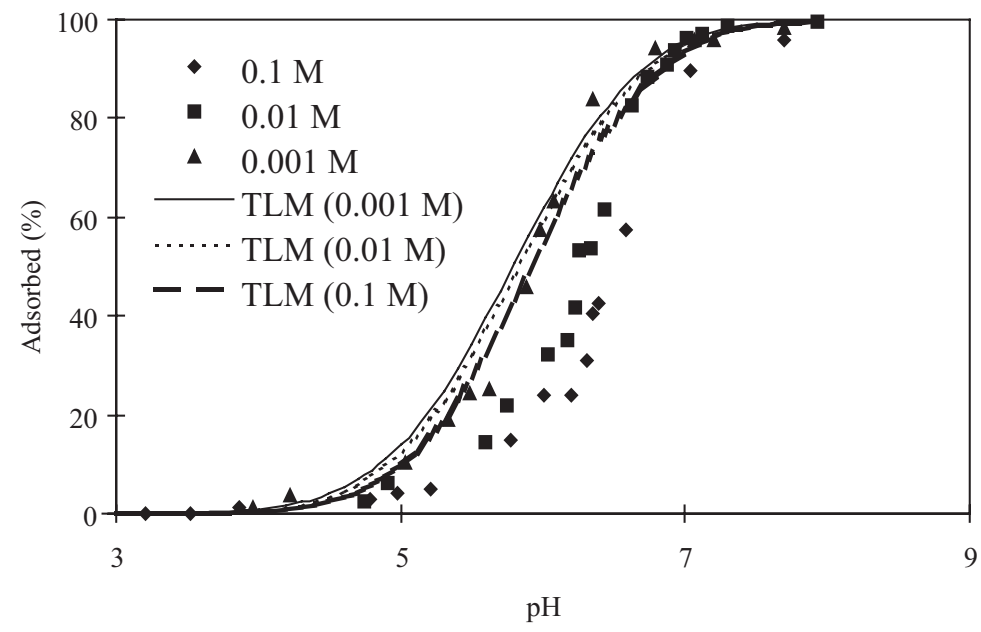

Figure 3. Adsorption of $\mathrm{Cu}^{2+}$ onto $1000^{\circ} \mathrm{C}$ sintered material (Adsorbent II) as a function of pH under various background $\mathrm{NaNO}_{3}$ concentrations. Lines denote TLM results using $\mathrm{SOCu}^{+}+\mathrm{SOCuOH}$ of Eq. (5) + Eq. (8). Symbols denote experimental data.

$(0.01 \mathrm{M}, 0.1 \mathrm{M})$, and the adsorption envelope shifts markedly to the right. The TLM simulation, in which Eqs. (5) and (8) are individually applied, does not yield satisfactory results, implying that the copper ions do not alone form a complex with the sintered material as $\mathrm{SOCu}^{+}$or $\mathrm{SOCuOH}$. The results of the simulation (Fig. 3) 


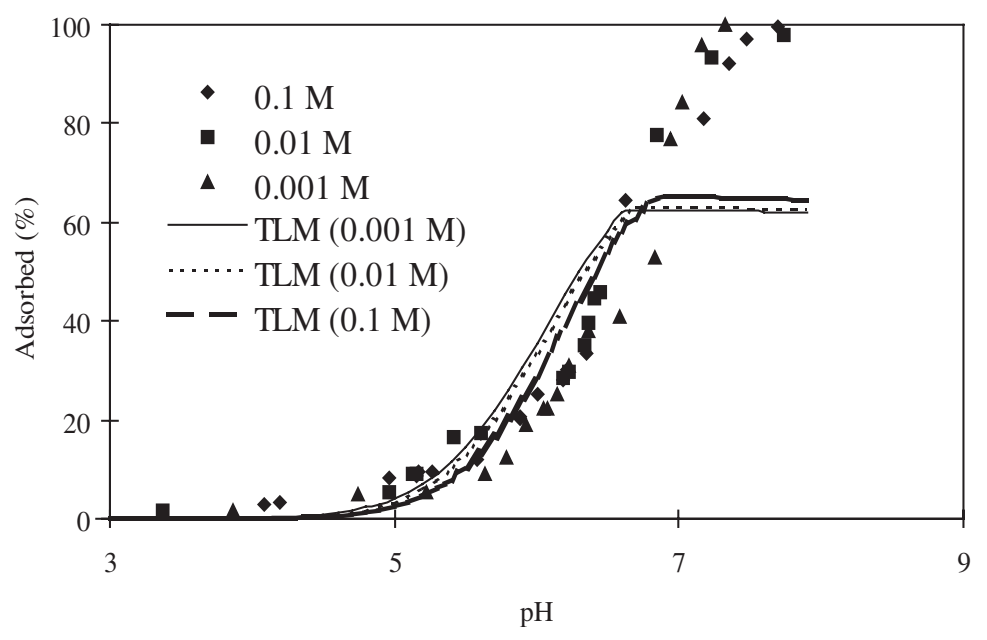

Figure 4. Adsorption of $\mathrm{Cu}^{2+}$ onto $1100^{\circ} \mathrm{C}$ sintered material (Adsorbent III) as a function of $\mathrm{pH}$ under various background $\mathrm{NaNO}_{3}$ concentrations. Lines denote TLM results using $\mathrm{SOCu}^{+}+\mathrm{SOCuOH}$ of Eq. (5) + Eq. (8). Symbols denote experimental data.

improve when the co-existence of $\mathrm{Cu}^{2+}$ and $\mathrm{Cu}(\mathrm{OH})^{+}$in the system (Eq. (5) + Eq. (8)) is accounted for. When the concentration of the background electrolyte is low $(0.001 \mathrm{M})$, the results of the TLM simulation is almost the same as the experimental data obtained from the $\mathrm{Cu}^{2+}+$ Adsorbent II system. When the copper ions react with Adsorbent III, no simulated surface complex reaction (Eqs. (5)-(9)) is consistent with the experimental results (Fig. 4).

Figures 5 and 6 present the results of the equilibrium adsorption of lead ions on the surfaces of Adsorbents II and III. The concentration of the background electrolyte (Fig. 5) influences the equilibrium adsorption of the lead ions on Adsorbent II, indicating that the lead ions adsorbed onto the surface of the $1000^{\circ} \mathrm{C}$ sintered material (Adsorbent II) may form an outer-sphere complex. However, this inference is inconsistent with the existing result ${ }^{[15]}$ and the result for the $1100^{\circ} \mathrm{C}$ sintered material (inner-sphere complexation). The simulation of the $\beta$-plane complex reaction (Eqs. (7) and (9)) is unsatisfactory, so a further simulation was conducted, assuming inner-sphere complexation according to the current experimental results. Figures 5 and 6 show the results of the TLM simulation in the case in which the lead ions adsorb onto the surfaces of Adsorbents II and III, respectively, and $\mathrm{Pb}^{2+}$ and $\mathrm{Pb}(\mathrm{OH})^{+}$co-exist in the system. The simulation results are similar to those for the adsorption reaction obtained when the lead ions are adsorbed onto the surface of the water treatment sludge. The simulation results most consistent with experimental results when $\mathrm{Pb}^{2+}$ and $\mathrm{Pb}(\mathrm{OH})^{+}$co-exist in the system. Figure 6 reveals that the simulation results that pertain to the lead ions adsorbed onto Adsorbent III are applicable only in acidic/neutral systems. These simulation results are the same as those concerning the adsorption of copper ions onto Adsorbent III.

Figures 7 and 8 depict the reactions of the copper ions and the lead ions with the four adsorbents used in this study. $\mathrm{pH}_{50}$ represents the $\mathrm{pH}$ when the adsorption ratio 


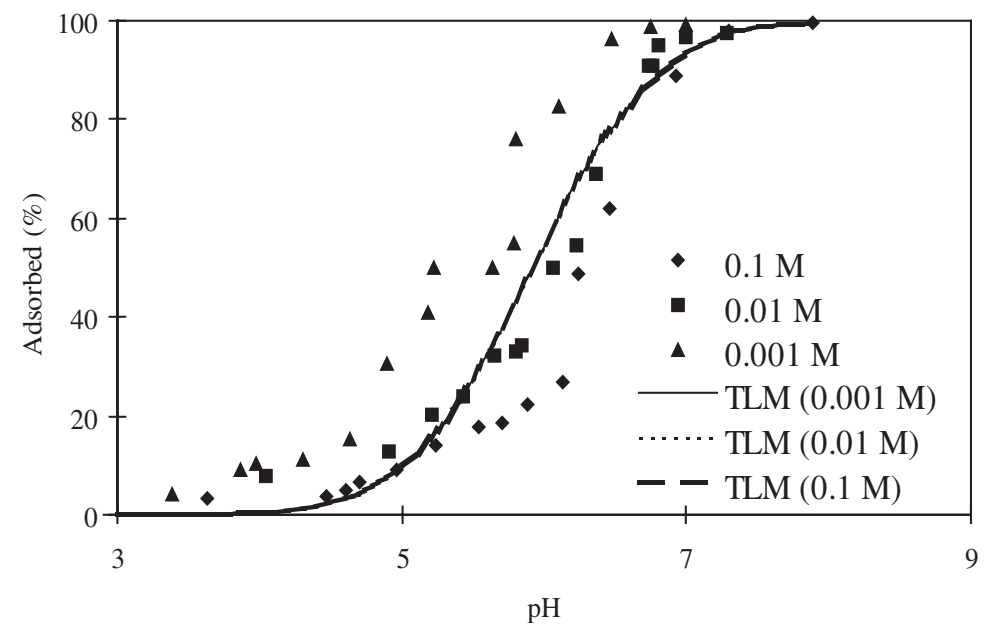

Figure 5. Adsorption of $\mathrm{Pb}^{2+}$ onto $1000^{\circ} \mathrm{C}$ sintered material (Adsorbent II) as a function of $\mathrm{pH}$ under various background $\mathrm{NaNO}_{3}$ concentrations. Lines denote TLM results using $\mathrm{SOPb}^{+}+\mathrm{SOPbOH}$ of Eq. (5) + Eq. (8). Symbols denote experimental data.

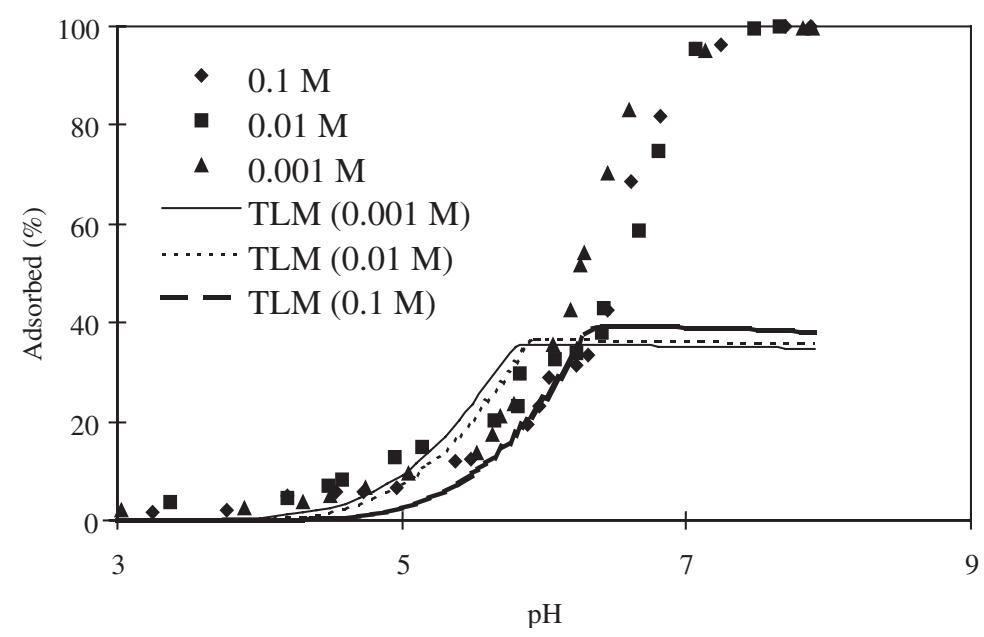

Figure 6. Adsorption of $\mathrm{Pb}^{2+}$ onto $1100^{\circ} \mathrm{C}$ sintered material (Adsorbent III) as a function of pH under various background $\mathrm{NaNO}_{3}$ concentrations. Lines denote TLM results using $\mathrm{SOPb}^{+}+\mathrm{SOPbOH}$ of Eq. (5) + Eq. (8). Symbols denote experimental data.

reaches $50 \%$, and specifies whether the adsorption occurs easily. According to Figs. 7 and 8 , the $\mathrm{pH}_{50}$ values of the four adsorbents follow the order, $\mathrm{pH}_{50-\mathrm{I}}<$ $\mathrm{pH} 50-\gamma-\mathrm{Al}_{2} \mathrm{O}_{3}<\mathrm{pH}_{50-\mathrm{II}}<\mathrm{pH}_{50-\text { III }}$. This result implies that the percentage of copper and lead ions adsorbed onto various oxides declines in the order of, water treatment sludge, $\gamma-\mathrm{Al}_{2} \mathrm{O}_{3}$, material (Adsorbent II) sintered at $1000^{\circ} \mathrm{C}$, and material (Adsorbent III) sintered at $1100^{\circ} \mathrm{C}$. The differences among various adsorbent 


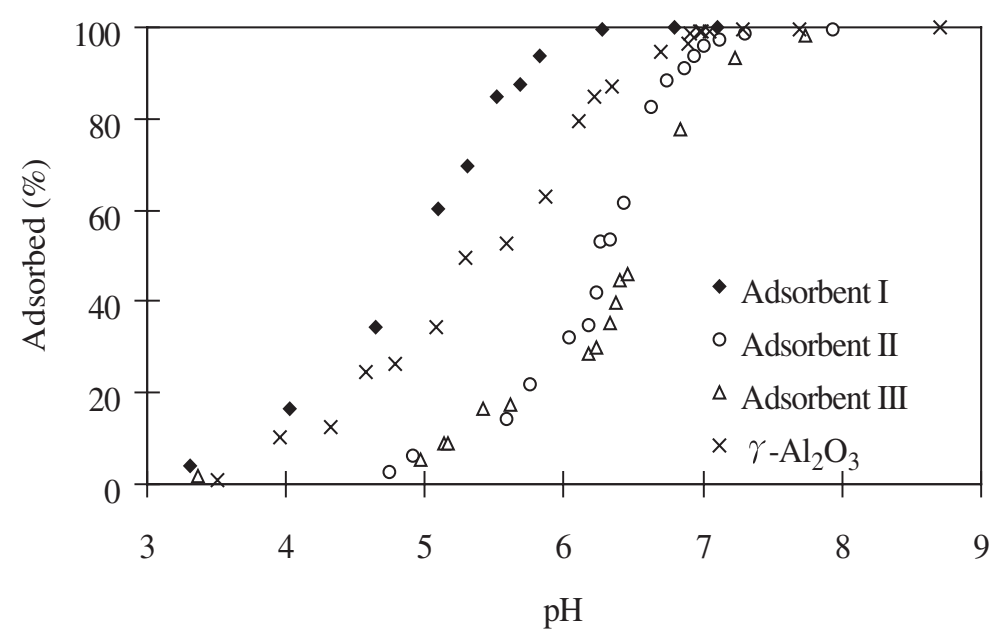

Figure 7. Adsorption of $\mathrm{Cu}^{2+}$ onto various oxide surfaces as a function of $\mathrm{pH}$.

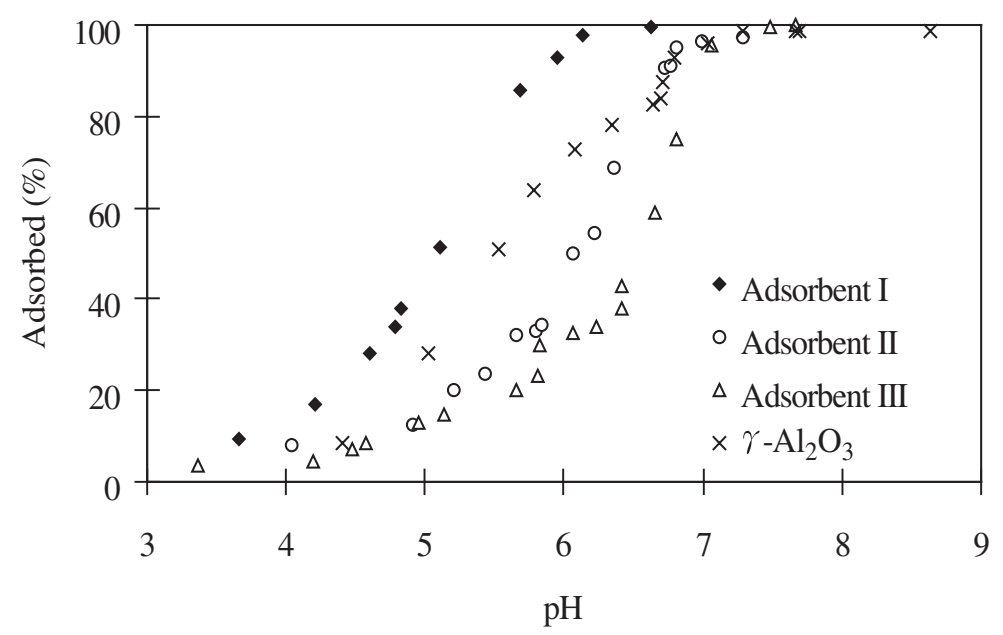

Figure 8. Adsorption of $\mathrm{Pb}^{2+}$ onto various oxide surfaces as a function of $\mathrm{pH}$.

surfaces may explain this finding. The water treatment sludge that is not sintered has a tiny-slice structure on its surface and provides a larger specific surface area than (about ten times that of) the sintered material. Even if the adsorption sites of the oxides do not change with temperature, the larger specific surface area may still facilitate adsorption.

Table 4 lists the intrinsic equilibrium constants of the four adsorbents of $\mathrm{Cu}^{2+}$ and $\mathrm{Pb}^{2+}$ in this study. Some discrepancy exists between all the simulation results and the experimental results. Although the water treatment sludge constitutes more than half of the $\mathrm{SiO}_{2}$, discrepancies remain between water treatment sludge and $\mathrm{SiO}_{2}$. Accordingly, the basic surface complexation parameters of $\mathrm{SiO}_{2}$ may not be wholly 
Table 4. The intrinsic equilibrium constant of $\mathrm{Cu}^{2+}$ and $\mathrm{Pb}^{2+}$ on different adsorbent surfaces.

\begin{tabular}{|c|c|c|c|c|}
\hline \multirow[b]{2}{*}{ Adsorbent } & \multicolumn{4}{|c|}{$\begin{aligned} \text { Surface reaction: } \mathrm{SOH}+\mathrm{M}^{2+} & =\mathrm{SOM}^{+}+\mathrm{H}^{+} \\
\mathrm{SOH}+\mathrm{M}^{2+}+\mathrm{H}_{2} \mathrm{O} & =\mathrm{SOMOH}+2 \mathrm{H}^{+}\end{aligned}$} \\
\hline & $\log K_{\mathrm{Cu}}^{\mathrm{int}}$ & $\log K_{\mathrm{CuOH}}^{\mathrm{int}}$ & $\log K_{\mathrm{Pb}}^{\mathrm{int}}$ & $\log _{\mathrm{PbOH}}^{\mathrm{int}}$ \\
\hline$\gamma-\mathrm{Al}_{2} \mathrm{O}_{3}$ & -8.50 & -8.90 & -8.55 & -9.00 \\
\hline I & -6.35 & -6.90 & -6.75 & -7.25 \\
\hline II & -6.15 & -7.55 & -5.00 & -6.75 \\
\hline III & -6.90 & -7.95 & -6.15 & -7.55 \\
\hline
\end{tabular}

consistent with those pertaining to the water treatment sludge, causing this discrepancy between the results of the TLM simulation and the experimental data. The other reason may attribute from site heterogeneity on oxide surfaces. The TLM is based on the assumption that adsorption occurs on only one type of site while oxide surfaces contain features such as steps and irregularly broken edges that contribute to site heterogeneity and, thus, specific binding energies at different surface sites. Several researchers have discovered evidence of site heterogeneity on oxide surfaces. ${ }^{[16-23]}$ Consequently, the inaccuracies of the of TLM simulation of adsorption systems may be attributed to the site heterogeneity on adsorbent surfaces.

The TLM model yields acceptable simulation results concerning the adsorption of the cations onto water treatment sludge and the sintered material sintered at $1000^{\circ} \mathrm{C}$ (Adsorbent II). However, the simulation undervalues the adsorption capacity of the material sintered at $1100^{\circ} \mathrm{C}$ (Adsorbent III). The discrepancy might follow from the surface precipitation caused by the cations and the surface of the adsorbent. Restated, the cations are removed from the system via precipitation rather than by complex reactions, so a discrepancy exists between the simulation results and the experimental data. Many studies ${ }^{[24-26]}$ have pointed out that heavy metals and oxide surfaces undergo a series of processes from adsorption, through hydrolysis to surface precipitation. As the $\mathrm{pH}$ or the concentration of cations in the system increases, the metal and oxides may precipitate as a solid phase that forms a new surface via mononuclear adsorption and multinuclear adsorption. Therefore, this study assumes that the removal of the copper ions and lead ions from the material sintered at $1100^{\circ} \mathrm{C}$ at high $\mathrm{pH}$ (Adsorbent III), is attributed to both adsorption and precipitation on the surface. The change in surface potential caused by the formation of surface precipitation may be an important factor that affects the adsorption characteristics of multicomponent oxides. However, no surface model has been developed to elucidate this effect.

This study demonstrates that the water treatment sludge left after the water purification process, and its sinter, can adsorb $\mathrm{Cu}$ and $\mathrm{Pb}$. The water treatment sludge and its sinter can therefore be feasibly used as adsorbents for wastewater treatment. 


\section{CONCLUSION}

The water treatment sludge that remains after the water purification process contains mainly $\mathrm{SiO}_{2}(54 \%), \mathrm{Al}_{2} \mathrm{O}_{3}(21 \%)$, and $\mathrm{Fe}_{2} \mathrm{O}_{3}(7 \%)$. The surface area of the sintered water treatment sludge declines from 30 to $2 \mathrm{~m}^{2} / \mathrm{g}$. According to SEM analysis, the sintered water treatment sludge has a finer and tighter surface structure than the unsintered sludge. The use of low-cost adsorbent, derived from water treatment sludge, has been examined as a replacement for the current expensive methods of removing heavy metals from wastewater. The concentration of the background electrolyte only slightly influences the adsorption of $\mathrm{Cu}$ and $\mathrm{Pb}$. Both $\mathrm{Cu}$ and $\mathrm{Pb}$ form an inner-sphere complex on the surface of the adsorbent. The results of TLM simulation imply that free ions $\left(\mathrm{Cu}^{2+}\right.$ and $\left.\mathrm{Pb}^{2+}\right)$ co-exist with their hydrolysates $\left(\mathrm{CuOH}^{+}\right.$and $\left.\mathrm{PbOH}^{+}\right)$on the surface of the adsorbent to generate inner-sphere complexes. Under the same conditions, the adsorption percentage of the copper ions and lead ions to various oxides follows the order water treatment sludge $>\gamma-\mathrm{Al}_{2} \mathrm{O}_{3}>$ material sintered at $1000^{\circ} \mathrm{C}>$ material sintered at $1100^{\circ} \mathrm{C}$. This study demonstrates that the water treatment sludge recycled in a sintering process does not include harmful, dissolved heavy metals, and can be used as an adsorbent to adsorb heavy metals during the treatment of wastewater.

\section{ACKNOWLEDGMENTS}

The authors would like to thank the National Science Council of the Republic of China for financially supporting this research under Contract No. NSC 90-2211E-002-038.

\section{REFERENCES}

1. Karius, V.; Hamer, K. pH and grain-size variation in leaching tests with bricks made of harbour sediments compared to commercial bricks. The Science of the Total Environment 2001, 278, 73-85.

2. Wiebusch, B.; Ozaki, M.; Watanabe, H.; Seyfried, C.F. Assessment of leaching tests on construction material made of incinerator ash (sewage sludge): investigations in Japan and Germany. Wat. Sci. Tech. 1998, 38, 195-205.

3. Okuno, N.; Takahashi, S. Full scale application of manufacturing bricks from sewage. Wat. Sci. Tech. 1997, 36, 243-250.

4. Basegio, T.; Berutti, F.; Bernardes, A.; Bergmann, C.P. Environmental and technical aspects of the utilization of tannery sludge as a raw material for clay products. J. European Ceramic Society 2002, 22, 2251-2259.

5. Gupta, G.; Torres, N. Use of fly ash in reducing toxicity of and heavy metals in wastewater effluent. J. Hazardous Materials 1998, 57, 243-248.

6. Ayala, J.; Blanco, F.; Garcia, P.; Rodriguez, P.; Sancho, J. Asturian fly ash as a heavy metals removal material. Fuel 1998, 77, 1147-1154. 
7. Meng, X.; Hua, Z.; Dermatas, D.; Wang, W.; Kuo, H.Y. Immobilization of mercury(II) in contaminated soil with used tire rubber. J. Hazardous Materials 1998, 57, 231-241.

8. Apak, R.; Tuten, E.; Hugul, M.; Hizal, M. Heavy metal cations retention by unconventional sorbents (red muds and fly ashes). Wat. Res. 1998, 32, 430-440.

9. Lopez, E.; Soto, B.; Arias, M.; Nunez, A.; Rubinos, D.; Barral, M.T. Adsorbent properties of red mud and its use for wastewater treatment. Wat. Res. 1998, 32, 1314-1322.

10. Mohan, D.; Gupta, V.K.; Srivastava, S.K.; Chander, S. Kinetics of mercury adsorption from wastewater using activated carbon derived from fertilizer waste material. Colloid Surf. A 2001, 177, 169-181.

11. Mohan, D.; Singh, K.P. Single- and multi-component adsorption of cadmium and zinc using activated carbon derived from bagasse-an agricultural waste. Wat. Res. 2002, 36, 2304-2318.

12. Hayes, K.F.; Leckie, J.O. Modeling ionic strength effects on cation adsorption at hydrous oxide/solution interfaces. J. Colloid Interface Sci. 1987, 115, 564-572.

13. Pepelis, C.; Hayes, K.F.; Leckie, J. Hydraql: a Program for the Complexation of Chemical Equilibrium Composition of Aqueous Batch Systems Including SurfaceComplexation Modeling of Ion Adsorption at the Oxide/Solution Interface, Technical Report No. 306, Environ. Eng. Sci. Dep. Civil Eng. Standford University, 1988.

14. Meng, X.; Latterman, R.D. Modeling ion adsorption on aluminum hydroxide modified silica. Environ. Sci. Technol. 1993, 27, 1924-1929.

15. Swallow, K.C.; Hume, D.N.; Morel, F.M.M. Sorption of copper and lead by hydrous ferric oxide. Environ. Sci. Technol. 1980, 14, 1326-1331.

16. Benjamin, M.M.; Leckie, J.O. Multiple-site adsorption of $\mathrm{Cd}, \mathrm{Cu}, \mathrm{Zn}$, and $\mathrm{Pb}$ on amorphous iron oxyhydroxide. J. Colloid Interface Sci. 1981, 79, 209-221.

17. Goldberg, S. Chemical modeling of anion competition on goethite using the constant capacitance model. Soil Sci. Soc. Am. J. 1985, 49, 851-856.

18. Violante, A.; Colombo, C.; Buondonno, A. Competitive adsorption of phosphate and oxalate by aluminum oxides. Soil Sci. Soc. Am. J. 1991, 55, 65-70.

19. Manning, B.A.; Goldberg, S. Modeling competitive adsorption of arsenate with phosphate and molybdate on oxide minerals. Soil Sci. Soc. Am. J. 1996, 60, 121-131.

20. Manning, B.A.; Goldberg, S. Modeling arsenate competitive adsorption on kaolinite, montmorillonite, and illite. Clays and Clay Minerals 1996, 44, 609-623.

21. Benyahya, L.; Garnier, J.M. Effect of salicylic acid upon trace-metal sorption $\left(\mathrm{Cd}^{2+}, \mathrm{Zn}^{2+}, \mathrm{Cu}^{2+}\right.$, and $\left.\mathrm{Mn}^{2+}\right)$ onto alumina, silica, and kaolinite as a function of pH. Environ. Sci. Technol. 1999, 33, 1398-1407.

22. Wu, C.H.; Lo, S.L.; Lin, C.F.; Kuo, C.Y. Modeling competitive adsorption of molybdate, sulfate, and selenate on $\gamma-\mathrm{Al}_{2} \mathrm{O}_{3}$ by the triple-layer model. J. Colloid Interface Sci. 2001, 233, 259-264. 
23. Wu, C.H.; Kuo, C.Y.; Lin, C.F.; Lo, S.L. Modeling competitive adsorption of molybdate, sulfate, selenate, and selenite using a Freundlich-type multicomponent isotherm. Chemosphere 2002, 47, 283-292.

24. Farley, K.J.; Dzombak, D.A.; Morel, F.M. A surface precipitation model for the sorption of cations on metal oxides. J. Colloid Interface Sci. 1985, 106, 226-242.

25. Charlet, L.; Manceau, A. X-ray adsorption spectroscopic study of the sorption of $\mathrm{Cr}$ (III) at the oxide-water interface II. Adsorption, coprecipitation, and surface precipitation on hydrous ferric oxide. J. Colloid Interface Sci. 1994, 168, $73-86$.

26. Katz, L.E.; Hayes, H.F. Surface complexation modeling I. Strategy for modeling monomer complex formation at moderate surface coverage. J. Colloid Interface Sci. 1995, 170, 477-490.

Received May 19, 2003 


\section{Request Permission or Order Reprints Instantly!}

Interested in copying and sharing this article? In most cases, U.S. Copyright Law requires that you get permission from the article's rightsholder before using copyrighted content.

All information and materials found in this article, including but not limited to text, trademarks, patents, logos, graphics and images (the "Materials"), are the copyrighted works and other forms of intellectual property of Marcel Dekker, Inc., or its licensors. All rights not expressly granted are reserved.

Get permission to lawfully reproduce and distribute the Materials or order reprints quickly and painlessly. Simply click on the "Request Permission/ Order Reprints" link below and follow the instructions. Visit the U.S. Copyright Office for information on Fair Use limitations of U.S. copyright law. Please refer to The Association of American Publishers' (AAP) website for guidelines on Fair Use in the Classroom.

The Materials are for your personal use only and cannot be reformatted, reposted, resold or distributed by electronic means or otherwise without permission from Marcel Dekker, Inc. Marcel Dekker, Inc. grants you the limited right to display the Materials only on your personal computer or personal wireless device, and to copy and download single copies of such Materials provided that any copyright, trademark or other notice appearing on such Materials is also retained by, displayed, copied or downloaded as part of the Materials and is not removed or obscured, and provided you do not edit, modify, alter or enhance the Materials. Please refer to our Website User Agreement for more details.

\section{Request Permission/Order Reprints}

Reprints of this article can also be ordered at http://www.dekker.com/servlet/product/DOI/101081ESE120027381 